\title{
KEJADIAN HIPERTENSI \\ (Studi Analitik Pada Pasien Dewasa di Wilayah Kerja Puskesmas Jongaya Kota Makassar)
}

\author{
${ }^{1}$ Maria Ester Tamungku, ${ }^{2}$ Andi Alim, ${ }^{3}$ Rusnita \\ ${ }^{1,2,3}$ Fakultas Kesehatan Masyarakat, Universitas Pejuang Republik Indonesia
}

\begin{abstract}
Abstrak
Hipertensi merupakan salah satu penyakit tanpa gejala atau the silent disaese. Hipertensi adalah keadaan dimana tekanan darah sistolik $\geq 140 \mathrm{mmHg}$ dan diastolik $\geq 90 \mathrm{mmHg}$. Penelitian ini bertujuan untuk mengetahui hubungan antara umur, aktifitas fisik, makanan asin atau garam, obesitas, keturunan atau gen dan stres dengan kejadian hipertensi. Penelitian ini menggunakan deskriptik analitik dengan pendekatan study cross sectional dengan sampel sebanyak 179 responden dengan teknik pengambilan sampel dengan secara purposive sampling. Sampel penelitian ini adalah pasien yang berkunjung di Puskesmas Jongaya dengan kriteria umur 25-45 tahun. Penelitian ini dilakukan di Puskesmas Jongaya Kecematan Tamalate Kota Makassar pada bulan Juni-Juli 2019. Hasil penelitian didapatkan bahwa ada hubungan antara umur $\mathrm{P}=0,000<\alpha=0,050$, aktifitas fisik $\mathrm{P}=0,003<\alpha$ $=0,050$, makanan asin atau garam $\mathrm{P}=0,008>\alpha=0,050$, obesitas $\mathrm{P}=0,004<\alpha=0,050$, keturunan atau gen $\mathrm{P}=$ $0,001>\alpha=0,050$ dan stres $\mathrm{P}=0,001>\alpha=0,050$ dengan kejadian hipertensi. Pada penelitian ini disarankan bagi masyarakat yang terkena penyakit hipertensi untuk selalu melakukan pemeriksaan 2 kali dalam semingu, untuk melakukan olahraga, menghindari makanan berminyak atau berlemak, mengkonsumsi kadar garam yang cukup dan melakukan pola hidup sehat.
\end{abstract}

Kata Kunci: Hipertensi; Umur; Aktifitas Fisik; Garam; Obesitas; Keturunan; Stress

\section{Pendahuluan}

WHO mencatat pada tahun 2013 sedikitnya sejumlah 972 juta kasus hipertensi, diperkirakan menjadi 1,15 milyar kasus pada tahun 2025 atau berkisar $29 \%$ dari total penduduk dunia menderita hipertensi, dimana 333 juta berada di Negara maju dan 639 sisanya berada dinegara berkembang termasuk Indonesia. Hipertensi juga menempati peringkat ke-2 dari 10 penyakit terbanyak pada pasien rawat jalan di Rumah Sakit di Indonesia. Penderitanya lebih banyak wanita (30\%) dan pria $(29 \%)$ sekitar $80 \%$ kenaikan kasus hipertensi terjadi terutama di negara berkembang (1).

Di Asia, tercatat 38,4 juta penderita hipertensi pada tahun 2000 dan diprediksiakan menjadi 67,4 juta orang pada tahun 2025. Di Indonesia, mencapai $17,21 \%$ dari populasi penduduk dan kebanyakan tidak terdeteksi (2). Menurut National basic health survey prevalensi hipertensi di Indonesia pada kelompok usia 15 - 24 tahun adalah 8,7\% pada kelompok usia 25 - 34 tahun adalah 14,7\%, kelompok umur 35 - 44 tahun $24,8 \%$ usia 45 - 54 tahun $35,6 \%$,usia 55 - 64 tahun $45,9 \%$ untuk usia 65 - 74 tahun57,6\% sedangkan lebih dari 75 tahun adalah 63,8\%, dengan prevalensi yang tinggi tersebut hipertensi yang tidak disadari jumlahnya bisa lebih tinggi lagi. Hal ini terjadi karena hipertensi dan komplikasinya, jumlahnya jauh lebih sedikit daripada hipertensi yang tidak ada gejala (3).

Riskesdas 2018 menunjukkan prevalensi penyakit tidak menular 
mengalami kenaikan jika dibandingkan dengan Riskesdas 2013, antara lain kanker, stroke, penyakit gagal ginjal kronis, diabetes mellitus, dan hipertensi. Prevelensi kanker naik dari 1,4\% menjadi $1,8 \%$, prevelensi stroke naik dari $7 \%$ menjadi $10,9 \%$, dan penyakit ginjal kronik naik dari 2\% mennjadi $3,8 \quad$ (4),(5). Berdasarkan pemeriksaan gula darah, diabetes mellitus naik dari 6,9 menjadi $8,9 \%$, dan hasil pengukuran tekanan darah, hipertensi naik dari $25 \%$ menjadi $34,1 \%$. Kenaikan prevelensi tidak menular ini berhubungan dengan pola hidup, antara lain merokok, konsumsi minuman berakohol, aktifitas fisik, serta tidak konsumsi buah dan sayur. Dan hasil Riskesdas di Makassar tahun 2007-2018 meningkat di tahun 2018 dengan prevelensi hipertensi berdasarkan hasil pengukuran pada penduduk umur $\geq 18$ tahun

Peningkatan tekanan darah atau hipertensi dipengaruhi juga oleh aktifitas fisik. Penelitian yang dilakukan oleh Mannan, Hasrin; Wahiduddin; Rismayanti (2012) mengenai faktor risiko kejadian hipertensi di wilayah kerja puskesmas bangkala Kabupaten Jeneponto adalah tekanan darah akan lebih tinggi pada saat melakukan aktifitas fisik yang lebih rendah ketika beristirahat (6). Kelebihan berat badan atau kegemukan (obesitas) juga menjadi pemicu timbulnya berbagai penyakit serius termasuk hipertensi akut. Berat badan berlebih apalagi mereka yang obesitas akan mengalami tekanan darah yang lebih tinggi dibanding dengan mereka yang mempunyai berat badan normal. Peningkatan tekanan darah ini ditemukan sepanjang hari, termasuk juga malam hari (7). Hasil penelitian menunjukkan ada hubungan yang signifikan antara IMT dengan hipertensi. Riwayat keluarga yang hipertensi berhubungan dengan kejadian pada anak yang akan hipertensi yang ditunjukan oleh penelitian Respati tahun 2007 (8). Hasil penelitiannya menunjukkan bahwa rata-rata tekanan darah saat bekerja dan beristirahat lebih tinggi pada responden yang salah satu atau kedua orang tuanya tidak hipetensi Tanjung, (2009) dalam Emerita Stefhany (2012) (9). Hasil penelitian dari Muhlisin dan Laksono (2011) tentang faktor stres terhadap kekambuhan pasien hipertensi didapatkan hasil, dari 70 responden distribusi tingkat stres responden menunjukan sebagian besar responden memiliki tingkat stres sedang yaitu sebanyak 53 responden (76\%) dan berat 17 responden (24\%), dan distribusi kekambuhan hipertensi menunjukan sebagian besar responden memiliki kekambuhan hipertensi dalam kategori kadang-kadang yaitu sebanyak 40 responden $(57 \%)$ dan 30 responden (43\%) dalam kategori sedang (10). 
Puskesmas Jongaya merupakan salah satu Puskesmas yang ada di kota Makassar, Kecamatan Tamalate Kota Makassar. Dengan peningkatan kejadian hipertensi yang mempengaruhi kesehatan masyarakat di Puskesmas Jongaya, dan jumlah peserta hipertensi dewasa pada tahun 2017 ada sebanyak 576 dan mengalami peningkatan di tahun 2018 sebanyak 580 peserta pada penderita hipertensi dewasa. Dalam penelitian ini, peneliti tidak akan menganalisi seluruh penderita hipertensi tetapi peneliti hanya tertarik untuk menganalisis kejadian hipertensi pada dewasa yang mengalami peningkatan setiap tahunnya. Dengan mengalami peningkatan kejadian hipertensi pada dewasa setiap tahun maka peneliti tertarik untuk meneliti hubungan apa saja yang dapat meningkatkan kejadian hipertensi pada pasien dewasa di Puskesmas Jongaya di Kota Makassar 2019.

\section{Metode Penelitian}

Jenis penelitian yang digunakan adalah analitik observasional dengan desain cross sectional untuk menjelaskan beberapa faktor-faktor penyebab hubungan kejadian hipertensi pada pasien dewasa. Lokasi penelitian dilaksanakan di Puskesmas Jongaya Kecamatan Tamalate, Kota Makassar. Populasi penelitian ini semua pasien rawat jalan yang berkunjung di Puskesmas Jongaya sebanyak 580 orang. Pengambilan sampel dengan menggunakan teknik purposive sampling, yaitu cara pengambilan sampel dilakukan dengan memilih sampel yang memenuhi kriteria penelitian sampai kurung waktu tertentu sehingga jumlah sampel terpenuhi (11). Adapun kriteria pasien yang dimaksud adalah pasien yang datang berkunjung di Puskesmas Jongaya Kota Makassar, pasien yang berusia 25 - 45 tahun yang berkunjung di Puskesmas Jongaya. Sedangkan, penentuan jumlah sampel berdasarkan pengembangan rumus yang ditemukan oleh Issac dan Newton tahun 1976 dalam Sugiono, 2014. Sehingga sampel yang dibutuhkan sebanyak 179 responden.

Cara pengumpulan data pada penelitian ini dengan menggunakan dua jenis data yaitu data primer yang diperoleh secara langsung dari responden dengan pengisian kuisioner yang diberikan langsung oleh si peneliti dan data sekunder yang diperoleh secara langsung dari Puskesmas Jongaya. Pengolahan data yang diperoleh dilakukan dengan langkahlangkahnya yaitu: screening, editing, coding, entry, cleaning dengan menggunakan bantuan SPSS kemudian dianalisis secara deskriptif dan analitik. Analisis secara deskriptif dengan analisis univariat untuk dilakukan terhadap setiap variabel dari hasil penelitian. Pada umumnya dalam analisis ini hanya 
menghasilkan distribusi dan presentase dari tiap variabel, Analisis Bivariat dilakukan untuk mengetahui hubungan variabel dependen dan independen dalam bentuk tabulasi silang (Cross Tabulation) dengan menggunakan komputerisasi program SPSS dengan uji statistic Chisquare jika tidak ada sel yang memiliki frekuensi yang diharapkan (E) kurang dari 5. Jika nilai $p$-value 0,05 maka $H 0$ ditolak, dengan taraf kesalahan 0,05 . Jika terdapat sel yang mempunyai nilai E kurang dari 5 maka menggunakan fisher exat test. Data yang telah diolah dan disajikan dalam bentuk tabel distribusi frekuensi kemudian disertai narasi atau penjelasan.

Kejadian hipertensi diukur dengan menggunakan manset tensimeter dan stetoskop dengan kriteria objektif hipertensi apabila tekanan darah pada pemeriksaan terakhir $>140 / 90 \mathrm{mmHg}$, variabel umur diukur berdasarkan tahun penelitian dikurangi dengan tahun lahir responden dengan kriteria objektif beresiko jika umur $\geq 36$ tahun, variabel aktivitas fisik atau olahraga diukur dengan menggunakan pertanyaan dalam konsioner kepada responden dengan kriteria objektif aktivitas fisik apabila melakukan olahraga selama $\geq 30$ menit dan 3-4 kali/minggu, variabel konsumsi makanan asin atau garam diukur dengan cara wawancara dengan metode Kuisioner Frekuensi Makan (SFFQ) dengan kriteria objektif tidak lebih dari 6 gram per hari, variabel status obesitas diukur berdasarkan indeks massa tubuh (IMT) dengan kriteria objektif obesitas jika hasil IMT $>25 \mathrm{~kg} / \mathrm{m}^{2}$. Keturunan atau Genetika diukur dengan cara wawancara dengan responden dengan kriteria objektif jika orang tua mengalami kejadian hipertensi, variabel stres diukur dengan kuesioner Depression, Anxiety, and Stress Scale (DASS) dengan kriteria objektif stres dengan nilai skor $\geq 53$.

\section{Hasil dan Pembahasan}

Umur atau usia adalah satuan waktu yang mengukur waktu keberadaan suatu benda atau makhluk, baik yang hidup maupun yang mati. Misalnya umur manusia dikatakan lima belas tahun di ukur sejak dia lahir hingga waktu umur itu dihitung.

Penelitian ini dilakukan dengan cara bertanya pada responden sesuai dengan kusioner dalam penelitian atau melakukan wawancara pada saat pengambilan obat karena responden telah diperiksa oleh dokter ataupun tenaga kesehatan yang bertugas di Puskesmas Jongaya Kota Makassar.

Tabel. 2 menunjukan bahwa dari 179 responden yang diteliti, ditemukan kelompok umur yang berisiko menderita hipertensi sebanyak 113 responden $(63,1 \%)$ sedangkan yang tidak berisiko sebanyak 66 orang $(36,9 \%)$. dari 113 
responden dengan kategori umur yang berisiko untuk terkena hipertensi didapatkan sebanyak 48 responden (42,5\%) yang menderita hipertensi dan 65 orang $(57,5 \%)$ yang tidak mengalami hipertensi. Dari hasil uji statistik, diperoleh nilai $P=$ Value $0,000<\alpha=0,05$ ini berarti bahwa Ho ditolak dan $\mathrm{Ha}$ diterima, sehingga ada hubungan yang bermakna antara umur dengan kejadian hipertensi di Puskesmas Jongaya Kota Makassar tahun 2019.

Dari hasil penelitian ini menunjukkan bahwa rata-rata pada usia 25-45 dapat terkena penyakit hipertensi tapi gejalanya belum nyata, dan jika umur bertambah dewasa maka dapat mengalami kejadian hipertensi dan pada penyakit ini sering kali tidak muncul gejalanya serta dengan gaya hidup yang kurang baik pula dapat dengan mudah terkena penyakit hipertensi dan hipertensi pula tidak memandang umur, karena itu tergantung dengan gaya hidup dan pola makan kurang baik dari seorang tersebut.

Penelitian ini sejalan dengan penelitian yang dilakukan oleh Lina Dwi Yoga Pratama (2016) hasil uji statistik diperoleh nilai $\mathrm{p}=0,026<0,050$, maka dapat disimpulkan bahwa ada hubungan anatara umur dengan tingkat hipertensi. Diperoleh pola hubungan yaitu semakin tinggi umur maka semakin tinggi tingkat hipertensi (12).
Aktifitas fisik adalah kegiatan dalam durasi waktu tertentu yang membutuhkan energi dan pergerakan otototot kerangka. Sedangkan olahraga yang berarti gerakan badan yang bersifat terstruktur dengan tujuan yang bersifatterstruktur dengan tujuan yang spesifik, biasanya untuk melatih anggota tubuh tertentu.

Kelompok responden yang melakukan aktifitas fisik atau berolahraga sebanyak 105 responden (58,7\%) dan yang tidak melakukan aktifitas fisik atau berolahrga sebanyak 74 repoden $(41,3 \%)$. Dari 105 responden yang melakukan aktifitas fisik didapatkan sebanyak 44 responden $(41,9 \%)$ yang menderita hipertensi dan 61 responden $(58,1 \%)$ yang tidak menderita hipertensi. Berdasarkan hasil uji statistik, diperoleh nilai $P=$ Value $0,003<\alpha=0,05$ (tabel 3) ini berarti bahwa Ho ditolak dan Ha diterima, sehingga ada hubungan bermakna antara aktifitas fisik atau olahraga dengan kejadian hipertensi di Puskesmas Jongaya Kota Makassar tahun 2019.

Aktifitas fisik atau olahraga yang dimaksud adalah seorang yang melakukan olahraga atau kegiatan yang membakar kalori tidak mudah terserang penyakit hipertensi dari pada seorang yang tidak melakukan aktifitas atau berolahraga. Penelitian ini menjelaskan bahwa seorang yang melakukan aktifitas berat atau ringan 
setiap harinya dan dalam waktu yang ditentukan yaitu $>3$ kali dalam semingu dalam waktu $>30$ menit beloraraga dan melakukan aktifitas ringan lainnya seperti memasak, menyapu, mengepel dan lainlainya yang dapat membakar kalori atau mengeluarkan keringat.

Penelitian ini sejalan dengan penelitian yang dilakukan oleh Lina Dwi Yoga Pratama (2016), dari hasil pengumpulan data distribusi frekuensi dapat diketahui bahwa ada sebagian besar aktifitas fisik responden terkategori rendah sebanyak 23 responden (59,0\%). Dengann hasil uji statistik diperoleh nilai $p=0,013<$ 0,05, maka dapat disimpulkan bahwa ada hubungan yang signifikan antara aktifitas fisik dengan tingkat hipertensi (12).

Makanan asin adalah makanan dengan kadar natrium tinggi. Dalam adalah senyawa ionik yang terdiri dari ion positif (kation) dan ion negatif (anion), sehingga membentuk senyawa netral (tanpa bermuatan). Garam terbentuk dari hasil reaksi asam dan basa.

$$
\text { Kelompok yang sering }
$$

mengkonsumsi makanan asing atau garam yang berlebihan sebanyak 111 responden (63\%) dan 68 responden $(38,0 \%)$ yang tidak mengkonsumsi makanan asing atau garam yang berlebihan (tabel 2). Berdasarkan hasil tabel silang dari 111 responden yang memiliki kebiasaan mengkonsumsi makanan asin atau garam yang di dapatkan 45 responden (40,5\%) yang menderita hipertensi dan 66 responden $(59,5 \%)$ yang tidak mengalami kejadian hipertensi (tabel 3).

Makanan asin atau garam merupakan salah satu kejadian hipertensi maupun pemicu dari penyakit hipertensi dan banyak responden sering mengatakan bahwa sering menambah garam dalam suatu makanan dan sering makan-makanan yang telah diolah seperti snack yang mengandung kadar garam tanpa responden sadari ataupun membaca kadar garam yang ada di dalam snack ataupun sering mengabaikan akan hal itu dan menganggap remeh.

Berdasarkan uji statistik, diperoleh nilai $\mathrm{P}=0,008<\alpha=0,05$ (tabel 3) ini berarti bahwa Ho ditolak dan Ha diterima, sehingga ada hubungan bermakna antara kebiasaan mengkonsumsi makanan asin atau garam dengan kejadian hipertensi di Puskesmas Jongaya Kota Makassar tahun 2019. Dari hasil penelitian ini menunjukkan bahwa jika seorang terlalu sering mengkonsumsi makan asin atau garam maka dapat berisiko terkena penyakit hipertensi.

Penelitian ini sejalan dengan penelitian yang dilakukan oleh Arifin, Rokhmad Rozinul (2015), hasil penelitian dari 17 responden dengan konsumsi garam tidak baik sebagian besar (64,7\%) responden mengalami hipertensi stadium 1 , 
$(17,6 \%)$ responden mengalami PreHipertensi, dan (17,6\%) responden normal. Sedangkan dari 19 responden dengan konsumsi garam baik sebagian besar $(57,9 \%)$ responden normal, $(36,8 \%)$ responden mengalami Pre-Hipertensi, $(5,3 \%)$ responden mengalami hipertensi stadium 1. Hasil analisis data dengan menggunakan uji statistik Chi-Square didapatkan nilai probabilitas $(\mathrm{P})=0,001<$ $\alpha(0,05)$, sehingga $\mathrm{H} 0$ di tolak yang berarti ada hubungan konsumsi garam dengan kejadian hipertensi di RT10 RW 05 Desa Tanjung Widoro Kecamatan Bungah Kabupaten Gresik (13).

Obesitas adalah suatu gangguan yang melibatkan lemak tubuh berlebihan yang meningkatkan risiko masalah kesehatan. Obesitas sering kali terjadi karena kalori yang masuk lebih banyak daripada yang dibakar melalui olahraga dan kegiatan normal sehari-hari.

Responden yang obesitas sebanyak 106 responden $(59,2 \%)$ dan 73 responden $(40,8 \%)$ yang tidak obesitas (tabel 2) . Dari 106 responden mengalami kejadian obesitas di dapatkan 44 responden (41,5\%) yang mengalami kejadian hipertensi dan 62 responden $(58,5 \%)$ tidak mengalami kejadian hipertensi (tabel 3).

Dari hasil penelitian ini menunjukkan bahwa jika seorang dengan berat badan berlebihan dapat berisiko mengalami hipertensi. Karena berat badan berlebihan tersebut seorang jarang melakukan aktifitas maka mereka mudah mengalami kelelahan dan sering tidak melakukan aktifitas fisik, dan dari kejadian tersebut maka seoarang yang berat badan berlebihan dengan mudah berisiko terserang ataupun mengalami kejadian hipertensi.

Berdasarkan uji statistik, diperoleh nilai $\mathrm{P}=0,004<\alpha=0,05$ ini berarti bahwa Ho ditolak dan Ha diterima, sehingga ada hubungan bermakna antara status obesitas responden dengan kejadian hipertensi di Puskesmas Jongaya Kota Makassar tahun 2019.

Penelitian ini tidak sejalan dengan penelitian yang dilakukan oleh Lina Dwi Yoga Pratama (2016), dari hasil pengumpulan data distribusi frekuensi berdasarkan obesitas dapat diketahui bahwa separuh responden obesitas sebanyak 19 responden $(48,7 \%)$ sama dengan yang tidak obesitas sebanyak 20 responden (51,3\%). Dengan hasil uji statistik diperoleh nilai $\mathrm{p}=0,272>0,05$, maka dapat disimpulkan bahwa tidak ada hubungan yang signifikan antara obesitas dengan tingkat hipertensi (12).

Keturunan adalah keturunan leluhur, artinya hubungan darah antara seorang dan orang lain bertujuan untuk meneruskan generasi keluarga (ibu, anak, cucu, dan seterusnya). 
Tabel 2 menggambarkan dari 115 responden $(64,2 \%)$ yang memiliki riwayat keturunan atau genetik dari orang tua yang menderita hipertensi dan 64 responden $(35,8 \%)$ yang tidak memiliki riwayat keturunan atau genetik dari orang tua yang menderita hipertensi. Dari 115 responden yang memilki riwayat keturunan atau genetik dari orang tua yang menderita hipertensi di dapatkan 48 responden (41,7\%) yang mengalami kejadian hipertensi dan 67 responden (58,3\%) tidak mengalami kejadian hipertensi.

Berdasarkan uji statistik, diperoleh nilai $\mathrm{P}=0,001<\alpha=0,05$ ini berarti bahwa Ho ditolak dan Ha diterima, sehingga ada hubungan bermakna antara responden yang memiliki riwayat keturunan atau genetik hipertensi dengan kejadian hipertensi di Puskesmas Jongaya Kota Makassar tahun 2019.

Dari hasil penelitian ini menunjukkan bahwa jika seorang dengan keturunan hipertensi dapat terjadi penyakit hipertensi. Berbagai penelitian dan study kasus menguatkan bahwa faktor keturunan merupakan salah satu penyebab terjadinya hipetensi, dimana jika di dalam keluarga atau orang tua ada yang menderita hipertensi $25-60 \%$ akan terjadi pada anaknya (14).

Penelitian ini sejalan dengan penelitian yang dilakukan oleh $\mathrm{Zul}$ Adhayani Arda, dkk (2018), menunjukan bahwa responden yang memiliki riwayat hipertensi (risiko ringgi) sebanyak 141 responden $(69,8 \%)$, dimana 88 responden di antaranya menderita hipertensi. Hasil uji statistik dengan odds rasio menunjukan bahwa riwayat hipertensi merupakan faktor risiko yang signifikan terhadap terjadinya hipertensi $\mathrm{OR}=6.13$, berarti responden yang memiliki riwayat hipertensi berisiko 6.13 kali lebih besar untuk menderita hipertensi dibandingkan responden yang tidak memiliki riwayat hipertensi. Tinggi garam yaitu $(p=0,003)$, dan dari hasil uji statistik menyatakan jika mengkomsunsi tinggi garam dapat berisiko terkena hipertensi (15).

Stres adalah gangguan mental yang dihadapi seseorang akibat adanya tekanan. Tekanan ini muncul dari kegagalan individu dalam memenuhi kebutuhan atau keinginannya. Tekanan ini berasal dari dalam diri, atau dari luar.

Kelompok responden yang mengalami stres sebanyak 122 responden $(68,2 \%)$ dan 57 orang $(33,8 \%)$ yang tidak mengalami stres (tabel 2). Dari 122 responden yang mengalami stres didapatkan 50 responden $(41,0 \%)$ yang mengalami kejadian hipertensi dan 72 responden $(59,0 \%)$ yang tidak mengalami kejadian hipertensi (tabel 3).

Berdasarkan uji statistik, diperoleh nilai $\mathrm{P}=0,001<\alpha=0,05$ ini berarti bahwa Ho ditolak dan Ha diterima, sehingga ada 
hubungan bermakna antara tingkat stres responden dengan kejadian hipertensi di Puskesmas Jongaya Kota Makassar tahun 2019.

Penelitian ini sejalan dengan hasil penelitian yang di lakukan oleh Deasy Eka Saputri (2010), Ada hubungan yang bermakna antara stres dengan hipertensi setelah dikontrol oleh variabel lain yaitu umur, status perkawinan, tingkat pendidikan, IMT, DM dan pengerluaran perkapita serta dikontrol pula oleh adanya interaksi umur dan stres yang berinteraksi negatif (antagonism), dimana umur mengurangi efek dari stres terhadap terjadinya hipertensi. Dengan proporsi hipertensi yang disebabkan adanya interaksi tersebut sebesar 3,2\% (16).

\section{Kesimpulan}

Berdasarkan hasil penelitian tentang Kejadian hipertensi (Studi Analitik Pada Pasien Dewasa di Wilayah Kerja Puskesmas Jongaya Kota Makassar) maka dapat disimpulkan sebagai berikut: Ada hubungan antara umur dengan kejadian hipertensi; Ada hubungan antara aktifitas fisik dengan kejadian hipertensi; Ada hubungan antara makanan asin atau garam dengan kejadian hipertensi; Ada hubungan antara antara obesitas dengan kejadian hipertensi; Ada hubungana antara keturunan atau gen dengan kejadian hipertensi; dan Ada hubungan antara stres dengan kejadian hipertensi.

\section{Saran}

Berdasarkan hasil penelitian dapat disarankan, maka peneliti merekomendasikan beberapa hal sebagai berikut: Disarankan kepada semua umur untuk selalu melakukan gaya hidup sehat agar terhindar dari penyakit hipertensi karena penyakit ini tidak memandang umur; Disarankan kepada masyarakat untuk selalu melakukan aktifitas fisik atau olahraga atau jalan sehat setiap hari dan melakukan aktifitas olahraga selama $\geq 30$ menit dengan frekuensi 3-4 kali dalam seminggu untuk membakar kalori di dalam tubuh; Diharapkan kepada masyarakat agar jangan terlalu banyak mengkomsusi makanan berminyak atau berlemak, dan jangan terlalu banyak makan-makanan asin setiap hari dan selalu melakukan pola hidup sehat agar terhindar dari penyakit tekanan darah tinggi; Diharapkan bagi penderita obesitas untuk menurunkan berat badan dan mengubah pola hidup sehat agar terhindar dari penyakit hipertensi; Diharapkan bagi yang mempunyai riwayat keturunan hipertensi untuk selalu melakukan pola hidup sehat agar terhindar dari penyakit hipertensi; Dan bagi penderita hipertensi disarankan meminum obat anti hipertensi dan melakukan pola hidup sehat setiap hari agar terhindar dari penyakit-penyakit yang menyangkut 
hipertensi seperti contohnya stroke, gagal jantung, dan gagal ginjal.

\section{Daftar Pustaka}

1. Triyanto E. Pelayanan keperawatan bagi penderita hipertensi secara terpadu. Yogyakarta Graha Ilmu. 2014;

2. Muhammadun AS. Hidup bersama hipertensi. Yogyakarta: In-Books. 2010;

3. Widjaja FF, Santoso LA, Barus NR V, Pradana GA, Estetika C. Prehypertension and hypertension among young Indonesian adults at a primary health care in a rural area. Med J Indones. 2013;22(1):39-45.

4. RI KK. Badan penelitian dan pengembangan kesehatan. Ris Kesehat Dasar. 2013;

5. RI KK. Hasil utama riskesdas 2018. Jakarta Kemenkes RI. 2018;

6. Mannan H. Faktor risiko kejadian hipertensi di wilayah kerja puskesmas bangkala kabupaten jeneponto tahun 2012. 2013;

7. Damayanti D. Sembuh Total Diabetes Asam Urat Hipertensi Tanpa Obat. Yogyakarta Pinang Merah Publ. 2013;73-122.

8. Respati A. Hubungan Aktifitas Fisik Dengan Hipertensi Ringan Pada Laki-Laki Usia 20-40 tahun di Kota Pariaman Tahun 2007. Tesis, 44,
Universitas Muhammadyah, Depok; 2007.

9. Stefhany E. Hubungan pola makan, gaya hidup, dan indeks massa tubuh dengan hipertensi pada pra lansia dan lansia di posbindu kelurahan depok jaya tahun 2012. Skripsi Paska Sarjana, Univ Indones Depok. 2012;

10. Muhlisin A, Laksono RA. Analisis pengaruh faktor stres terhadap kekambuhan penderita hipertensi di puskesmas Bendosari Sukoharjo. 2013;

11. Hidayat AA. Metode penelitian kebidanan dan teknik analisis data. Jakarta salemba Med. 2007;43-4.

12. Pramana LDY. Faktor-Faktor Yang Berhubungan Dengan Tingkat Hipertensi Di Wilayah Kerja Puskesmas Demak II. UNIMUS; 2016.

13. Arifin, Rozinul R. Hubungan Konsumsi Garam Dengan Kejadian Hipertensi Pada Warga RT 10 RW 05 Desa Tanjung Widoro Kecamatan Bungah Kabupaten Gresik. Univ Nahdlatul Ulama Surabaya [Internet]. 2015; Available from:

http://repository.unusa.ac.id/id/eprin $\mathrm{t} / 183$

14. Marliani L. 100 Question \& Answers Hipertensi. Elex Media 
Komputindo; 2013.

15. Arda ZA, Mustapa M. Hipertensi dan Faktor Risikonya di Puskesmas Motolohu Kabupaten Pohuwato.

Gorontalo J Public Heal. 2018;1(1):32-8.

16. Saputri DE. Hubungan Stres Dengan Hipertensi Pada Penduduk Di Indonesia Tahun 2007. Univ Indones. 2010; 
Tabel. 1 Distribusi Karakteristik Responden Berdasarkan Jenis Kelamin, Umur, Pendidikan, Pekerjaan di Puskesmas Jongaya Kota Makassar Tahun 2019. $n=179$

\begin{tabular}{lcc}
\hline \multicolumn{1}{c}{ Karakteristik } & Frekuensi (n) & Persentase (\%) \\
\hline Jenis Kelamin & & \\
\hline Laki-laki & 72 & 40,2 \\
Perempuan & 107 & 59,8 \\
\hline Pendidikan & & \\
\hline Tidak Sekolah & 13 & 3,9 \\
SD & 15 & 4,5 \\
SMP & 38 & 11,5 \\
SMA & 71 & 21,5 \\
Perguruan Tinggi & 42 & 12,7 \\
\hline Pekerjaan & & \\
\hline Ibu Rumah Tangga & 77 & 43 \\
Wiraswasta & 35 & 19,6 \\
Petani/Buruh & 22 & 12,3 \\
Pegawai Negeri Sipil & 27 & 15,3 \\
Dan Lain-Lain & 18 & 10,1 \\
\hline Sumber: Data Primer, &
\end{tabular}

Sumber: Data Primer, 2019

Tabel. 2 Distribusi Responden Berdasarkan Tekanan Darah, Umur, Aktifitas Fisik, Makanan Asing, Obesitas, Keturunan dan Stres di Puskesmas Jongaya Kota Makassar Tahun 2019. $n=179$

\begin{tabular}{lcc}
\hline \multicolumn{1}{c}{ Variabel } & Frekuensi (n) & Persentase (\%) \\
\hline Tekanan Darah & 59 & 33 \\
Hipertensi & 120 & 67 \\
Tidak Hipertensi & 113 & \\
\hline Umur & 66 & 63,1 \\
Berisiko & & 36,9 \\
Tidak berisiko & 105 & 58,7 \\
\hline Aktifitas Fisik & 74 & 41,3 \\
Beraktifitas & & \\
Tidak beraktifitas & 111 & 62 \\
Makanan Asin & 68 & 38,0 \\
Berisiko & & \\
Tidak berisiko & 106 & 59,2 \\
\hline Status Obesitas & 73 & 40,8 \\
Obesitas & & \\
Tidak obesitas & 115 & 64,2 \\
\hline Keturunan/Gentik & 64 & 35,8 \\
Berisiko & & \\
Tidak berisiko & 122 & 68,2 \\
\hline Stres & 57 & 31,8 \\
Stres & &
\end{tabular}

Sumber: Data Primer, 2019. 
Tabel. 3 Distribusi responden berdasarkan hubungan umur, aktifitas fisik, makanan asin, obesitas, keturunan/genetik dan stres dengan kejadian hipertensi pada pasien dewasa di Puskesmas Jongaya Kota Makassar 2019.

\begin{tabular}{|c|c|c|c|c|c|c|c|}
\hline \multirow{3}{*}{ Variabel } & \multicolumn{4}{|c|}{ Tekanan Darah } & \multicolumn{2}{|c|}{ Total } & \multirow{3}{*}{$p$} \\
\hline & \multicolumn{2}{|c|}{ Hipertensi } & \multicolumn{2}{|c|}{ Tidak Hipertensi } & \multirow{2}{*}{$\mathbf{n}$} & \multirow{2}{*}{$\%$} & \\
\hline & $\mathbf{n}$ & $\%$ & $\mathbf{n}$ & $\%$ & & & \\
\hline \multicolumn{8}{|l|}{ Umur } \\
\hline Berisiko & 48 & 42,5 & 65 & 57,5 & 113 & 100 & \multirow{2}{*}{0,000} \\
\hline Tidak Berisiko & 11 & 16,7 & 55 & 83,3 & 66 & 100 & \\
\hline \multicolumn{8}{|l|}{ Aktifitas Fisik } \\
\hline Beraktifitas & 44 & 41,9 & 61 & 58,1 & 105 & 100 & \multirow{2}{*}{0,003} \\
\hline Tidak beraktifitas & 15 & 20,3 & 59 & 79,7 & 74 & 100 & \\
\hline \multicolumn{8}{|c|}{ Makanan Asin/Garam } \\
\hline Berisiko & 45 & 40,5 & 66 & 59,5 & 111 & 100 & \multirow{2}{*}{0,008} \\
\hline Tidak berisiko & 14 & 20,6 & 54 & 79,4 & 68 & 100 & \\
\hline \multicolumn{8}{|l|}{ Status Obesitas } \\
\hline Obesitas & 44 & 41,5 & 62 & 58,5 & 106 & 100 & \multirow{2}{*}{0,004} \\
\hline Tidak Obesitas & 15 & 20,5 & 58 & 79,5 & 73 & 100 & \\
\hline \multicolumn{8}{|c|}{ Keturunan/Genetik } \\
\hline Berisiko & 48 & 41,7 & 67 & 58,3 & 115 & 100 & \multirow{2}{*}{0,001} \\
\hline Tidak Berisiko & 11 & 17,2 & 53 & 82,8 & 64 & 100 & \\
\hline \multicolumn{8}{|l|}{ Stres } \\
\hline Stres & 50 & 41,0 & 72 & 59,0 & 122 & 100 & \multirow{2}{*}{0,001} \\
\hline Tidak Stres & 9 & 15,8 & 48 & 84,2 & 57 & 100 & \\
\hline
\end{tabular}

Sumber: Data Primer, 2019. 